\title{
Increased incidence of acute calculous cholecystitis observed during COVID-19 social restrictions
}

\author{
Mark C. Murphy ${ }^{1}$ (1) $\cdot$ Philip J. Dempsey ${ }^{1} \cdot$ Ciara D. Gillespie $^{1} \cdot$ Alexandra N. Murphy $^{1} \cdot$ Michelle M. J. McNicholas $^{1}$
}

Received: 3 October 2020 / Accepted: 1 March 2021 / Published online: 11 March 2021

(c) Royal Academy of Medicine in Ireland 2021

\begin{abstract}
Purpose In response to the outbreak of COVID-19 in Ireland, the government implemented a nationwide stay-at-home order, with the closure of all non-essential businesses. During this period, there was a significant increase in supermarket expenditure. It has been shown that stress, anxiety and boredom are triggers for unhealthy eating habits. Fat consumption is a risk factor for both the development of gallstones and, additionally, the development of acute calculous cholecystitis. The aim of this study was to assess the incidence of acute calculous cholecystitis during the nationwide lockdown and compare it to the same period one year prior.

Methods A retrospective review of all emergency abdominal imaging performed during the first 5 weeks of the lockdown was completed using the hospital PACS (picture archiving and communication system). All cases of acute calculous cholecystitis were identified and compared with the same period 1 year prior.

Results Eighteen cases of acute calculous cholecystitis were identified from 24 March to 27 April 2020. Eleven cases were identified during the same period in 2019. This represented an increase of 63\%. Non-COVID-19-related emergency presentations decreased during this period, and imaging of emergency presentations decreased by $24 \%$. The rate of scans positive for acute cholecystitis more than doubled $(p<0.037)$.

Conclusion A statistically significant increase in cases of acute calculous cholecystitis was observed during a nationwide lockdown during the COVID-19 pandemic. It is hypothesised that this is due to increased consumption of fatty foods during this period due to stress, anxiety and boredom.
\end{abstract}

Keywords Cholecystitis · COVID-19 · Fatty food consumption · Gallbladder · Social restrictions

\section{Introduction}

The first case of the novel coronavirus Sars-Cov-2 causing the disease COVID-19 was confirmed in Ireland on 29 February 2020 . The first death was reported 13 days later on

Mark C. Murphy

markmurphy1608@gmail.com

Philip J. Dempsey

philipjdempsey@gmail.com

Ciara D. Gillespie

ciaragill@gmail.com

Alexandra N. Murphy

alexandra.murphy87@gmail.com

Michelle M. J. McNicholas

michellemcnicholas@mac.com

1 Department of Radiology, Mater Misericordiae University Hospital, Eccles St., Dublin 7, Ireland
March 11th. On the same day, the World Health Organisation declared a global pandemic. In response to the spread of the virus, the Irish government, like many others around the world, implemented measures to curtail the spread of the virus. Initial restrictions were announced on March 12th with the closure of schools and universities and advice for people to work from home where possible. Following this, a nationwide lockdown was implemented on March 24th with a shelter-in-place order and the closure of all non-essential businesses. The public were permitted to leave their homes only to purchase essential supplies and for exercise once a day within a $2-\mathrm{km}$ (1.2 mile) radius of the home. Supermarket sales increased by $27 \%$ during the month of March making it the highest grossing month of grocery sales ever recorded in Ireland [1]. It is hypothesised that there was also an increase in food consumption, including that of fatty foods; this was reported in multiple media outlets as well as on social media. 
Gallstones are solid rounded particles composed of a combination of cholesterol and bilirubin that form within the gallbladder and biliary system [2]. The primary risk factor for the development of gallstones is a high fat diet [3, 4].

Cholecystitis refers to inflammation of the gallbladder, which can be an acute or chronic process. The vast majority of cases of acute cholecystitis are caused by impacted gallstones in the cystic duct, for which the term acute calculous cholecystitis is used. A small minority of patients can develop acute cholecystitis in the absence of gallstones, known as acalculous cholecystitis, generally occurring in the setting of immunosuppression, particularly in critically unwell or burns patients [5-7].

Gallbladder contraction is stimulated in response to a fatty meal through the enzyme cholecystokinin. This is produced by the intestinal enteroendocrine cells of the duodenum in response to fatty acids [8]. Frequent gallbladder contraction in the presence of gallstones increases the risk of a stone becoming impacted in the cystic duct and, therefore, the risk of developing acute calculous cholecystitis [9]. For this reason, a high fat diet increases the risk of both gallstone formation and the development of acute cholecystitis.

During the national lockdown, the majority of hospital outpatient visits were cancelled, and non-COVID-19 hospital activity fell dramatically. There was a marked reduction in presentations to the emergency department with nonCOVID-19 conditions, and there was a significant reduction in the volume of medical imaging performed. Despite the reduction in acute presentations and the reduction in imaging overall, it was anecdotally observed that there appeared to be an increase in the number of patients presenting acute calculous cholecystitis. The aim of this study was to assess the impact of the national lockdown on the incidence of acute calculous cholecystitis.

\section{Methods}

A retrospective search was performed of the hospital PACS system. All imaging performed during a 5-week period from the day the shelter-in-place order was implemented on 24 March 2020-27 April 2020 was assessed. The following studies were included: ultrasound abdomen, ultrasound gallbladder, CT abdomen and pelvis, CT KUB, CT urogram, $\mathrm{CT}$ liver and MRCP. Interventional radiology procedures were also assessed for cholecystostomy to ensure no cases had been missed. All CT thorax-abdomen-pelvis studies ordered by the emergency department and general surgical teams were also included, given a hospital strategy to include CT thorax for all surgical presentations to ED during the COVID-19 pandemic. The reports of all studies were assessed for a diagnosis of acute cholecystitis. The search was repeated in the same manner for the corresponding period in 2019. Statistical analysis was performed with a $\mathrm{X}$-squared test for binary calculations and a $t$-test for normally distributed data. Statistical significance was set at $\alpha=0.05$.

\section{Results}

Between 24 March and 27 April 2020, there were 420 studies which met the inclusion criteria and were assessed. This consisted of 327 CTs, 73 ultrasounds and 20 MRCPs. A detailed breakdown is provided in Table 1. During the corresponding period in 2019, there were 553 studies comprising of 368 CTs, 155 ultrasounds and 30 MRCPs. This represented a $24 \%$ decrease in imaging of acute presentations as a result of the nationwide lockdown.

There were 11 cases of acute calculous cholecystitis diagnosed during the 5 -week period in 2019. There were 18 cases of acute cholecystitis diagnosed during the same period in 2020. This represents a $63 \%$ increase in cases of acute cholecystitis during the period of national lockdown.

The 11 cases diagnosed in 2019 represented $2 \%$ of studies performed. The 18 cases diagnosed in 2020 represents $4.3 \%$ of studies performed. This was statistically significant (chi-squared $=4.35$. $p$-value $=0.037$ ).

Of the 18 patients diagnosed with acute calculous cholecystitis during the national lockdown, 8 patients were swabbed for COVID-19. The remaining 10 were not swabbed due to low clinical suspicion. Of the 8 patients swabbed, 7 tested negative. One patient tested positive for COVID-19; however, this was 8 days after diagnosis with two prior normal swabs. This was clinically judged to represent a secondary nosocomial case of COVID- 19.

There was no significant difference in the management of the two groups. Of the 18 patients diagnosed with acute calculous cholecystitis during the national lockdown, 12 patients were managed conservatively, 5 patients underwent

Table 1 Study breakdown

\begin{tabular}{lrr}
\hline & 2019 & 2020 \\
\hline Ultrasound abdomen & 128 & 66 \\
Ultrasound gallbladder & 27 & 7 \\
MRCP & 30 & 20 \\
CT abdomen and pelvis & 239 & 200 \\
CT renal/KUB & 84 & 60 \\
CT liver & 7 & 7 \\
CT abdominal aorta & 4 & 2 \\
CT Thorax abdomen and pelvis (ED/ & 34 & 58 \\
$\quad$ Gen Surg) & & \\
Total & 553 & 420 \\
\hline
\end{tabular}


IR cholecystostomy and one patient underwent a laparoscopic cholecystectomy.

Of the 11 patients diagnosed with acute calculous cholecystitis in 2019, 7 were managed conservatively on their initial admission. Three patients underwent IR cholecystostomy, and one patient underwent a laparoscopic cholecystectomy.

\section{Discussion}

This study demonstrates a significant increase in the incidence of acute calculous cholecystitis despite a reduction in non-COVID-19-related emergency presentations during a period of national lockdown, when people were confined to home. It is known that increased fat consumption contributes both to gallstone formation and acute cholecystitis [9]. The period of lockdown was the busiest period ever reported for supermarket expenditure [1]. The significantly increased supermarket expenditure suggests increased consumption of food and beverage. It is well recognised that there is a clear association between stress and anxiety and comfort eating. In addition, boredom and confinement are also triggers for unhealthy eating habits [10-14]. Increased food consumption and 'comfort eating' have been identified in many media publications during lockdown, with tips on how to remain on a healthy diet despite the stress of confinement [14, 15]. For many, the ritual of mealtime and eating provided a welcome diversion from the boredom of a socially and physically diminished existence in confined quarters $[16,17]$. It is assumed that the intake of fatty foods also increased during this period, where many people passed some time cooking and baking at home.

The overall number of acute cholecystitis cases increased by $63 \%$. When accounting for the decrease in hospital presentations and overall imaging performed, cases more than doubled.

None of the patients diagnosed with acute cholecystitis during the national lockdown initially tested positive for COVID-19. One patient tested positive on the 8th day of his admission however had two preceding negative swabs. This was felt to represent a nosocomial infection. Thus, COVID19 did not appear to have a direct impact per se, on the incidence of acute calculous cholecystitis.

There was no significant difference in the management between the two groups. One patient in each group proceeded to laparoscopic cholecystectomy during their admission. Five patients during the national lockdown underwent IR cholecystostomy compared with 3 patients in 2019. The remaining cases were managed conservatively in both groups.

It is acknowledged that a limitation to this study is the small numbers of cases. However, the relative increase in cases of acute cholecystitis during the national lockdown is considerable, and the causality of increased fatty food consumption is intuitive.

One possible confounder for the significant increase in the proportion of positive scans that were positive for acute cholecystitis is the possibility that the acutely unwell patients were more likely to continue to present, while the less unwell symptomatic patients stayed at home, decreasing the volume of overall studies while leading to a relative increase in positive studies. Conversely, however, it is considered plausible that some patients with mild acute calculous cholecystitis may have failed to present to the healthcare service due to anxiety related to COVID-19 or that a greater proportion of these patients were treated with oral antibiotics in the community.

\section{Conclusion}

A statistically significant increase in cases of acute calculous cholecystitis was observed during the Irish national lockdown due to COVID-19 pandemic. It is hypothesised that this is due to increased consumption of fatty foods during this period.

\section{References}

1. http://www.kantarworldpanel.com. Ireland grocery market share

2. Murphy MC, Gibney B, Gillespie C et al (2020) Gallstones top to toe: what the radiologist needs to know. Insights Imaging 11:13. https://doi.org/10.1186/s13244-019-0825

3. Friedman GD (1993) Natural history of asymptomatic and symptomatic gallstones. Am J Surg 165:399

4. Clavien PA, Baillie J (Eds) (2006) Diseases of the gallbladder and bile ducts: diagnosis and treatment, Second Edition. WileyBlackwell Press.https://doi.org/10.1002/9780470986981

5. Morris CR, Hohf RP, Ivy AC (1952) An experimental study of the role of stasis in the etiology of cholecystitis. Surgery 32:673

6. Bortoff GA, Chen MY, Ott DJ, Wolfman NT, Routh WD (2000) Gallbladder stones: imaging and intervention. Radiographics 20(3):751-766

7. Kantsevoy SV (2001) Gallstones and biliary disease. Prim Care 28:591

8. Ziessman HA (2001) Cholecystokinin cholescintigraphy: clinical indications and proper methodology. Radiol Clin North Am 39:997. Kalloo AN

9. Roslyn JJ, DenBesten L, Thompson JE Jr, Silverman BF (1980) Roles of lithogenic bile and cystic duct occlusion in the pathogenesis of acute cholecystitis. Am J Surg 140:126

10. Naja F, Rena H (2020) Nutrition amid the COVID-19 pandemic: a multi-level framework for action. European journal of clinical nutrition, 1-5. 20 https://doi.org/10.1038/s41430-020-0634-3

11. Anton SD, Miller PM (2005) Do negative emotions predict alcohol consumption, saturated fat intake, and physical activity in older adults? Behav Modif 29:677-688. https://doi.org/10.1177/ 0145445503261164.[PubMed][CrossRef][GoogleScholar] 
12. Macht M (1999) Characteristics of eating in anger, fear, sadness and joy. Appetite 33:129-139. https://doi.org/10.1006/ appe.1999.0236.[PubMed][CrossRef][GoogleScholar]

13. Macht M (2008) How emotions affect eating: a five-way model. Appetite 50:1-11. https://doi.org/10.1016/j.appet.2007.07.002. [PubMed][CrossRef][GoogleScholar]

14. Venema V (2020) Coronavirus: should I worry about my lockdown eating?. BBC online. https://www.bbc.co.uk/news/stories52329529 BBC 24/4/20

15. Lambert V (2020) How to stop binge eating during lockdown. The Telegraph online. https://www.telegraph.co.uk/health-fitness/ nutrition/beat-erratic-eating-lockdown/
16. Dunn K (2020) Coronavirus lockdown diets look the same the world over: bread, beans, and comfort food. Fortune, April. https:// fortune.com/2020/04/18/coronavirus-cooking-comfort-food-beansbread-lockdown-diet-menu-yeast-covid-19

17. Jordan LA (2020) Coronavirus: overeating at the moment? You're not the only one. https://graziadaily.co.uk/life/health-fitness/ coronavirus-overeating-junk-food/

Publisher's Note Springer Nature remains neutral with regard to jurisdictional claims in published maps and institutional affiliations. 